\title{
Environmental surface sampling for SARS-CoV-2 around hospitalized patients with COVID-19 in a tertiary care hospital
}

\author{
Varun Goel', Savita Gupta ${ }^{2}$, Vivek Gupta ${ }^{3}$, Ajay Kumar Sahni ${ }^{4}$ \\ ${ }^{1}$ Assistant Professor, ${ }^{4}$ Professor and Head, Department of Microbiology, ${ }^{2}$ Assistant Professor, Department of \\ Anaesthesia, ${ }^{3}$ Associate Professor, Department of Pathology, Government Institute of Medical Sciences, \\ Greater Noida, Uttar Pradesh, India
}

A B S TR A C T

Background: The contamination of patients' surroundings by severe acute respiratory syndrome coronavirus 2 (SARS-CoV-2) remains understudied. Discordant findings of SARS-CoV-2 RNA in environmental samples were noted in many reports. Aims and Objectives: The study assessed the extent and persistence of environmental surface contamination in real-world surfaces around COVID-19 patients. Materials and Methods: We sampled the surroundings of two intensive care unit (ICU) and one ward that were occupied by laboratory-confirmed coronavirus disease 2019 (COVID-19) patients. Frequently touched environmental surfaces near patients were swabbed before and after daily environmental disinfection. Results: Of 355 environmental samples, $6(1.69 \%)$ were positive by real-time reverse-transcription polymerase chain reaction assay. Among those, 5 of $75 \mathrm{ICU}$ samples (6.67\%) and 1 of 75 ward environmental samples $(1.33 \%)$ in the pre-fumigation areas occupied by COVID-19 positive patients were positive. No samples obtained within the first $2 \mathrm{~h}$ of fumigation and surface disinfection was found to be positive. Conclusion: Surrounding environment of symptomatic COVID-19 patients can get contaminated and in cases of asymptomatic COVID-19 patients, contamination of their surroundings was an uncommon phenomenon. Strict contact barrier precaution, routine cleaning with disinfectants are mandatory hospital infection control practices in the management of patients infected with SARS-CoV-2.

Key words: COVID-19; Environmental contamination; SARS-CoV-2; Surface;

Access this article online

Website:

http://nepjol.info/index.php/AJMS

DOI: 10.3126/ajms.v13i2.41266

E-ISSN: 2091-0576

P-ISSN: 2467-9100

Copyright (c) 2022 Asian Journal of Medical Sciences

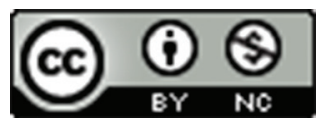

This work is licensed under a Creative Commons Attribution-NonCommercial 4.0 International License.

Transmission; Virus

\section{INTRODUCTION}

Environmental contamination and the quantification of the viable virus that can be isolated from the surroundings of patients with severe acute respiratory syndrome coronavirus 2 (SARS-CoV-2) admitted in the critical care wards are ambiguous. Limited studies pertaining to these kinds of studies are documented. Coronavirus disease 2019 (COVID-19) disease caused by SARS-CoV-2 has emerged as a global pandemic and the top public health priority for many countries. ${ }^{1}$ Hospitalized patients with COVID-19 may contaminate their surroundings and impose risks for health care workers and sanitary staff. ${ }^{2-4}$ SARS-CoV-2 can spread via respiratory droplets, bodily fluids, or contaminated surfaces. ${ }^{5}$
The SARS-CoV-2 virus may be transmitted to healthcare workers from an infected patient through several ways: by large droplets generated by coughs or sneezes that may splatter directly on the worker's face; from fomite transmission to the nose, face, or mouth when a worker may contact a surface contaminated by droplet fomites; and eventually by aerosol transmission by inhalation of fine particles containing the virus aerosolized from the respiratory system of the patient or could be due to shedding from contaminated clothing, become airborne for a while.,

There is ongoing concern that patients can become infected to COVID-19 through person-to-person spread and environment-to-person spread. Although the SARS-CoV-2 
virus can be acquired by exposure to fomites, yet the contamination of patients' surroundings by SARS-CoV-2 is largely documented by few studies ${ }^{8-11}$ overseas, limited as and none from the Indian subcontinent. This information will be able to inform risk assessments and infection prevention and control measures, to limit onwards transmission to protect health care workers.

The study assessed the extent and persistence of environmental surface contamination in real-world surfaces around COVID-19 patients in multiple outpatient and inpatient settings that followed strict COVID-19 risk mitigation strategies of SARS-CoV-2. It also identified environmental surfaces and fomites which may play a role in the onwards transmission of COVID-19. This information will pave way for policy decisions on the effectiveness of environmental cleaning and Infection control protocols.

\section{Aims and objectives}

To assess the extent and persistence of environmental surface contamination in real-world surfaces around COVID-19 patients in multiple outpatient and inpatient settings.

\section{MATERIALS AND METHODS}

This prospective observational study was approved by the local Institutional Review Board (GIMS/ IEC/HR/2021/05). The study was performed from 13 Jan 2021 to 12 Mar 2021 at a tertiary care hospital which is a designated hospital for treating severe and critical COVID-19 patients with five dedicated intensive care units (ICUs) for COVID-19 patients. During the study period, the hospital admitted more than 600 COVID-19 patients, of whom more than 100 were treated in the ICU. Total of 355 surfaces were sampled from two ICUs and ward according to World Health Organization protocols for COVID-19 surface sampling. ${ }^{12}$ All COVID-19 patients were identified by reverse transcriptase-polymerase chain reaction (RTPCR) inhouse testing for SARS-CoV-2 on admission. Patients in the wards were encouraged to wear a triple layer surgical mask at all times. Laboratory technical staff collecting the surface samples was trained in infection prevention and control procedures including standard precautions, personal protective equipment, hand hygiene, and N95 masks to minimize their own risk of infection when in close contact with COVID-19 infected patients. COVID-19 patients in ICU and ward were separated by a minimum bed space of $2 \mathrm{~m}$. Background information about the hospital layout was collected and the exact sampling locations were determined. The date, time, frequency, and details of disinfection activities were collected for all sampling locations.

In different areas of hospital including ICU and ward before fumigation and disinfection samples were taken. Similarly, environmental samples taken within $2 \mathrm{~h}$ of fumigation and disinfection were considered as post fumigation samples. Surfaces were sampled using wet cotton swabs. Sterile synthetic-tipped swabs (HiMedia; India) pre-moistened with viral transport medium were used for the surface sampling. While wet swab was moved in at least two different directions while rotating the swab stick, gentle pressure onto the surface was applied. Each swab surface area was of around $25 \mathrm{~cm}^{2}$. Field control blanks were taken by moistening the swab and placing directly into the tubes with Viral Transport Media (VTM) (HiMedia; India), without any surface sampling. Control blanks were taken to know if any cross-contamination has occurred during surface sample collection. The sample swabs were then submerged in $2 \mathrm{~mL}$ viral transport medium. After labeling the vial, placed in a self-sealing bag and cleaned the outside of the sealed bag with a $60-80 \%$ ethanol solution just prior to leaving the contaminated area. Then, cleaned sealed bag was placed in another unused similar self-sealing bag and transported to the laboratory. Each swab sample in VTM was vortexed and centrifuged at $13,000 \times \mathrm{g}$ for $1 \mathrm{~min}$, and supernatant was used for nucleic acid extraction by Thermofisher RNA Extraction kit (M/s Invitrogen Bio services Pvt. Ltd; India) in Automated RNA extractor (Thermo Scientific ${ }^{\mathrm{TM}}$ KingFisher $^{\mathrm{TM}}$ Flex System). Real-Time RT-PCR was performed to detect the presence or absence of ORF1 $\mathrm{ab}$ and $\mathrm{N}$ gene using Taqman probe-based multicolor Meril COVID-19 One-step RTPCR Kit (Meril Diagnostics; India) with an analytical accuracy of $<5$ RNA copies/reaction in QuantStudio ${ }^{\mathrm{TM}}$ 5 Real-TimePCR system (Applied Biosystems).

\section{Statistical analysis}

Data thus collected were entered into a computer-based spreadsheet for analysis using SPSS statistical software (Version 21) (IBM Corp., NY, USA).

\section{RESULTS}

A total of 355 environmental samples including ventilators, perfusion pumps, bed rails, doorknob, bedside table, bed controller, call button, and floor were collected using pre-moistened sterile swabs in two ICU and one ward (Table 1).

Among those, 6 of 180 (3.33\%) environmental samples in pre-fumigation areas occupied by COVID-positive patients were found positive. Viral RNA was detected during pre-fumigation phase in ICU in 5 of 75 samples $(6.67 \%)$, 


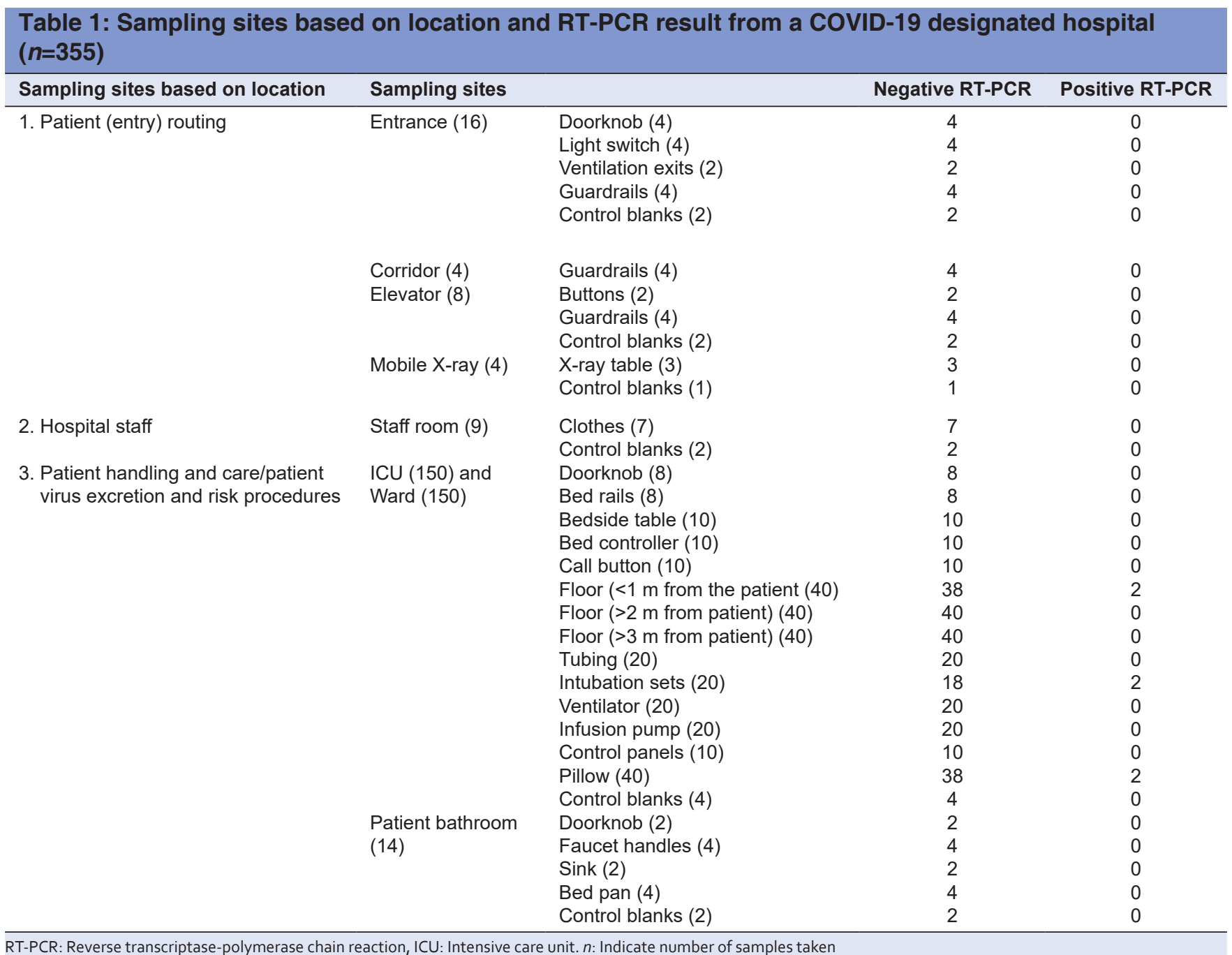

which was higher than contamination rate than those of the wards with less severe patients $(1.33 \%)$ (Table 2$)$.

Clinical characteristics of patients closest to the environmental surface sample varied by day of illness (median, day 8; the presence of symptoms (66.7\% symptomatic). Among these two were from infusion sets of patients who were symptomatic. Viral RNA was found at the pillow at the head end of two different patients among which one of the patients was asymptomatic. One environmental sample from the floor area $<1$ meter from one patient on high flow oxygen was found to be contaminated with SARS-CoV-2 genes. Among ward, out of 75 environmental samples collected, one sample from the floor area $<1$ meter from one patient was positive. All samples from outside the ward and ICUs, in the corridor, lift, Hospital staff clothes and mobile X-ray table were negative by real-time RT-PCR. The positive test rate for SARS-CoV-2 RNA across all surfaces in pre-fumigation phase across testing sites was 3.33\% (6 of 180). No viral RNA was detected after post fumigation within 2 hours of disinfection from 175 samples from any area in the ICU or wards.

\section{DISCUSSION}

Because COVID-19 is predominantly transmitted through droplet and contact routes, droplet and contact precautions should have overriding importance. ${ }^{13}$ Viable SARS-CoV-2 virus has been detected in bodily fluids other than respiratory particles, such as blood, feces, and urine of infected persons, but current studies does not indicate that these contribute to major routes of transmission. ${ }^{14,15}$ Bathroom vents transmission have been implicated in 10 cases in a study from Seoul by Hwang et al., ${ }^{16}$ though it is not possible to conclude whether transmission was associated with fecal aerosols or respiratory aerosols, or some other source unrelated to the vents.

In our hospital as a policy, we have actively promoted infection control measures in the hospital area with 


\begin{tabular}{|c|c|c|c|c|c|c|}
\hline \multicolumn{7}{|c|}{ Pre-fumigation phase $(n=180)$} \\
\hline \multirow[t]{2}{*}{ Area } & \multirow[t]{2}{*}{ Sampling locations } & \multirow[t]{2}{*}{$\begin{array}{l}\text { Positive } \\
\text { RT-PCR }\end{array}$} & \multirow[t]{2}{*}{$\begin{array}{c}\text { CT value of } \\
\text { surface samples }\end{array}$} & \multirow[t]{2}{*}{$\begin{array}{l}\text { Time since last surface } \\
\text { disinfectant/fumigation }\end{array}$} & \multicolumn{2}{|c|}{$\begin{array}{c}\text { Clinical data of patient closest to } \\
\text { collected environmental surface } \\
\text { samples }\end{array}$} \\
\hline & & & & & Day of Illness & $\begin{array}{l}\text { Patient } \\
\text { symptomatic }\end{array}$ \\
\hline ICU & Intubation set & Yes & 29.30 & $6 \mathrm{~h}$ & 13 & Yes \\
\hline \multirow{4}{*}{$(n=75)$} & Intubation set & Yes & 25.50 & $6 \mathrm{~h}$ & 11 & Yes \\
\hline & Head end from pillow & Yes & 24.35 & $6 \mathrm{~h}$ & 8 & No \\
\hline & Head end from pillow & Yes & 17.00 & $6 \mathrm{~h}$ & 2 & Yes \\
\hline & Floor $<1 \mathrm{~m}$ from patient & Yes & 31.7 & $6 \mathrm{~h}$ & 5 & Yes \\
\hline Ward & Floor $<1 \mathrm{~m}$ from patient & Yes & 27.11 & $7 \mathrm{~h}$ & 9 & No \\
\hline
\end{tabular}

$(n=75)$

Post-fumigation phase $(n=175)$. No environmental surface including ICU $(n=75)$ and ward $(n=75)$ contamination with SARS-CoV 2 was found. Ct value: cycle threshold. Cycle threshold refers to number of cycles a sample has to be amplified before the virus can be detected by the fluorescent signal and cross the threshold in RT-PCR; a lower cycle threshold value may indicate a higher viral load. RT-PCR: Reverse transcriptase-polymerase chain reaction, ICU: Intensive care unit

enforcement of hand hygiene practice and environmental cleaning, and all hospitalized patients were provided with surgical masks as source control to reduce the amount of environmental contamination. High-touch housekeeping surfaces like doorknobs, bedrails, light switches, light switches in patient-care areas were cleaned and/or disinfected more frequently. In addition, we have been actively promoting hand hygiene among our hospitalized patients. Indeed, viral particle was not found on various hospital objects during post disinfection phase which can be sources of nosocomial transmission via direct contact. Our results show environmental contamination of the COVID-19 patients' surroundings by SARS-CoV-2 may not be a common way for COVID-19 to spread especially if seen in the context of a strict disinfection policy.

Compared to the wards, the ICU with the symptomatic patients, environmental surfaces were more heavily contaminated especially by patients who were on high flow oxygen. Viral nucleic acid was detected in ICU in $6.67 \%$, which was higher than contamination rate than those of the wards with less severe patients $(1.33 \%)$. In one study in an oncology unit by Shah et al., ${ }^{17}$ the positive test rate for SARS-CoV-2 RNA across all surfaces in the outpatient/inpatient units was $0.5 \%$ (1 of 204).

No viral RNA was detected after post fumigation of 175 samples from any area including the ICUs and ward. All laboratory personnel involved in the investigation need to be trained in infection prevention and control procedures including standard precautions, personal protective equipment, hand hygiene, and N95 masks to minimize their own risk of infection.

Because here aim was to evaluate hospital surface contamination, we did not evaluate airborne transmission. Moreover, there is a lack of standardized microbiological air sampling protocols currently for SAR-CoV-2 as seen in the World Health Organization 2020, ${ }^{12}$ and Pan et al. ${ }^{18}$

\section{Limitations of the study}

Our study has several limitations. First, we tested only for viral nucleic acid and did not perform the viral culture to test viability and actual infectivity by live SARS-CoV-2. Further details of transmission can be obtained by genome sequencing of COVID-19 isolates. Second, air sampling could not be performed due to the absence of equipment and also due to lack of standardization of air samples. Despite the limitations, we believe that the findings reported here may help to guide prevention and control of COVID-19.

\section{CONCLUSION}

Present study demonstrated that SARS-CoV-2 presence on environmental surfaces as detected by PCR in different hospital areas was extremely low, especially in the ward. The results of this study are reassuring and should reduce concerns for patients and health care providers about infection transmission from environmental surfaces in hospital areas when strict mitigation strategies against SARS-CoV-2 transmission are instituted. In conclusion, surroundings of COVID-19 patients can be contaminated and asymptomatic COVID-19 patients do contaminate their surroundings and impose risks for others in contact with them. However, transmission through surfaces is not a common way that COVID-19 spreads. Understanding environmental transmission early is necessary to the implementation of public health measures to slow the spread of any novel disease throughout work. Strict standard precaution, routine cleaning, and disinfection are mandatory in the management of patients infected with SARS-CoV-2. 


\section{ACKNOWLEDGMENTS}

Laboratory Staff of Molecular Diagnostics and Research Laboratory, Government Institute of Medical Sciences, Greater Noida - 201 310, Gautam Buddha Nagar U.P., India.

\section{REFERENCES}

1. Zhu N, Zhang D, Wang W, Li X, Yang B, Song J, et al. A novel coronavirus from patients with pneumonia in China, 2019. N Engl J Med. 2020;382(8):727-733.

\section{https://doi.org/10.1056/NEJMoa2001017}

2. Kampf G, Todt D, Pfaender S and Steinmann E. Persistence of coronaviruses on inanimate surfaces and their inactivation with biocidal agents. J Hosp Infect. 2020;104(3):246-251.

https://doi.org/10.1016/j.jhin.2020.01.022

3. Cai J, Sun W, Huang J, Gamber M, Wu J and He G. Indirect virus transmission in cluster of COVID-19 cases, Wenzhou, China, 2020. Emerg Infect Dis. 2020;26(6):1343-1345.

https://doi.org/10.3201/eid2606.200412

4. Ong SW, Tan YK, Chia PY, Lee TH, Ng OT, Wong MS, et al. Air, surface environmental, and personal protective equipment contamination by severe acute respiratory syndrome coronavirus 2 (SARS-CoV-2) from a symptomatic patient. JAMA. 2020;323(16):1610-1612.

https://doi.org/10.1001/jama.2020.3227

5. Mohamadi $M$, Babington-Ashaye $A$, Lefort $A$ and Flahault A. Risks of infection with SARS-CoV-2 due to contaminated surfaces: A scoping review. Int J Environ Res Public Health. 2021;18(21):11019.

https://doi.org/10.3390/ijerph182111019

6. Li YH, Fan YZ, Jiang L and Wang HB. Aerosol and environmental surface monitoring for SARS-CoV-2 RNA in a designated hospital for severe COVID-19 patients. Epidemiol Infect. 2020;148:e154. https://doi.org/10.1017/S0950268820001570

7. Cheng VC, Wong SC, Chan VW, So SY, Chen JH, Yip CC, et al. Air and environmental sampling for SARS-CoV-2 around hospitalized patients with coronavirus disease 2019 (COVID-19). Infect Control Hosp Epidemiol. 2020;41(11):1258-1265.

https://doi.org/10.1017/ice.2020.282

8. Moore G, Rickard H, Stevenson D, Aranega-Bou P, Pitman J, Crook A, et al. Detection of SARS-CoV-2 within the healthcare environment: A multi-centre study conducted during the first wave of the COVID-19 outbreak in England. J Hosp Infect. 2021;108:189-196.

https://doi.org/10.1016/j.jhin.2020.11.024
9. Aytogan $\mathrm{H}$, Ayintap $\mathrm{E}$ and Yilmaz NO. Detection of coronavirus disease 2019 viral material on environmental surfaces of an ophthalmology examination room. JAMA Ophthalmol. 2020;138(9):990-993.

https://doi.org/10.1001/jamaophthalmol.2020.3154

10. Shin KS, Park HS, Lee J and Lee JK. Environmental surface testing for severe acute respiratory syndrome coronavirus 2 (SARS-CoV-2) during prolonged isolation of an asymptomatic carrier. Infect Control Hosp Epidemiol. 2020;41(11):1328-1330. https://doi.org/10.1017/ice.2020.300

11. Azuma K, Yanagi U, Kagi N, Kim H, Ogata M and Hayashi M. Environmental factors involved in SARS-CoV-2 transmission: Effect and role of indoor environmental quality in the strategy for COVID-19 infection control. Environ Health Prev Med. 2020;25(1):66. https://doi.org/10.1186/s12199-020-00904-2

12. World Health Organization. Surface Sampling of Coronavirus Disease (COVID-19): A Practical "how to" Protocol for Health Care and Public Health Professionals, 18 February 2020, version 1.1. Geneva: World Health Organization; 2020. https:// apps.who.int/iris/handle/10665/331058 [Last accessed on 2020 June 09].

13. Fink JB, Ehrmann S, Li J, Dailey P, McKiernan P, Darquenne C, et al. Reducing aerosol-related risk of transmission in the era of COVID-19: An interim guidance endorsed by the international society of aerosols in medicine. J Aerosol Med Pulm Drug Deliv. 2020;33(6):300-304.

https://doi.org/10.1089/jamp.2020.1615

14. Gupta S, Parker J, Smits S, Underwood J and Dolwani S. Persistent viral shedding of SARS-CoV-2 in faeces a rapid review. Colorectal Dis. 2020;22(6):611-620. https://doi.org/10.1111/codi.15138

15. Xiao F, Tang M, Zheng X, Liu Y, Li X and Shan H. Evidence for Gastrointestinal Infection of SARS-CoV-2. Gastroenterology. 2020;158(6):1831-1833.e3. https://doi.org/10.1053/j.gastro.2020.02.055

16. Hwang SE, Chang JH, Oh B and Heo J. Possible aerosol transmission of COVID-19 associated with an outbreak in an apartment in Seoul, South Korea, 2020. Int J Infect Dis. 2021;104:73-76

https://doi.org/10.1016/j.ijid.2020.12.035

17. Shah MR, Jan I, Johns J, Singh K, Kumar P, Belarmino N, et al. SARS-CoV-2 nosocomial infection: Real-world results of environmental surface testing from a large tertiary cancer center. Cancer. 2021;127(11):1926-1932. https://doi.org/10.1002/cncr.33453

18. Pan M, Lednicky JA and Wu CY. Collection, particle sizing and detection of airborne viruses. J Appl Microbiol. 2019;127(6):1596-1611.

https://doi.org/10.1111/jam.14278

\footnotetext{
Authors Contribution:

VG- Concept and design of the study, statistical analysis and interpretation, preparation of manuscript; SG- Concept and design of the study, Interpreted the results, reviewed the literature and manuscript, prepared first draft of manuscript; VGU- Reviewed the literature, revision of the manuscript; AKS- Interpreted the results, revision of the manuscript

Work attributed to:

Government Institute of Medical Sciences, Greater Noida - 201 310, Uttar Pradesh, India

Orcid ID:

Dr Varun Goel - (iD https://orcid.org/0000-0002-9194-727X

Dr Savita Gupta - (1) https://orcid.org/0000-0002-3104-7368

Dr Vivek Gupta - id https://orcid.org/0000-0002-7830-4616

Dr Ajay Kumar Sahni - (D) https://orcid.org/0000-0002-4187-7648

Source of Support: Nil, Conflict of Interest: None declared.
} 